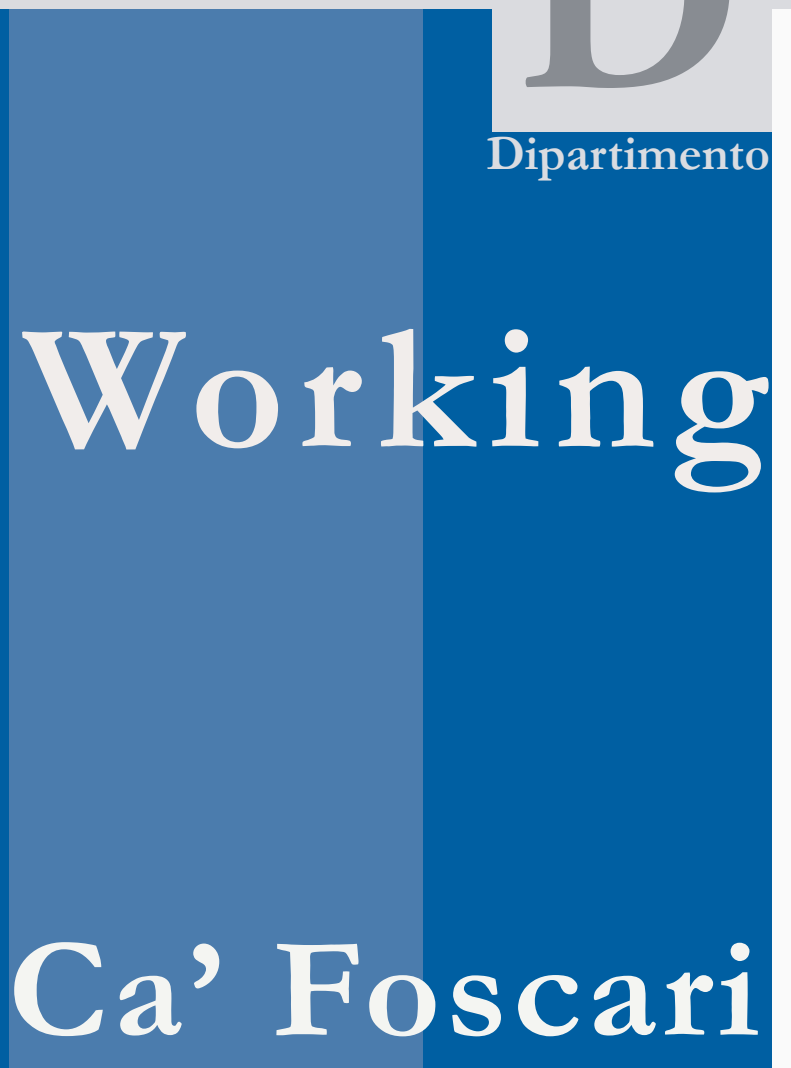

Scienze Economiche

Paper

Department

of Economics

University of

Venice

Elisabetta Trevisan

Job Security and New Restrictive Permanent Contracts. Are

Spanish Workers More

Worried of Losing Their Job? 


\title{
Job Security and New Restrictive Permanent Contracts. Are Spanish Workers More Worried of Losing Their Job?
}

\author{
Elisabetta Trevisan \\ Università Ca' Foscari Venezia \\ CCP (Center for Corporate Performance), Aarhus Business School
}

January 2007

\begin{abstract}
This paper investigates the impact of the introduction of new restrictive permanent contracts on the perceived job security of the workers in Spain. The perceived job security is strongly influenced by the characteristics of individuals and their distribution within groups. Comparing heterogeneous groups could make the traditional DID estimator biased. To address this issue I combine the propensity score matching DID with a fixed effect estimator. The analysis is conducted using data from the ECHP Survey for Spain from 1995 to 2000. The result is that this reform has a positive impact only for one targeted group, i.e. the young workers and no effect for the others. Several robustness checks are performed.
\end{abstract}

\section{Keywords}

Job Security, Firing Costs, Evaluation Policy, Fixed Effect Estimator

\section{JEL Codes}

C14, C33, J28

Address for correspondence:

Elisabetta Trevisan

Department of Economics

Ca’ Foscari University of Venice

Cannaregio 873, Fondamenta S.Giobbe

30121 Venezia - Italy

Phone: (++39) 0412349231

Fax: (++39) 0412349176

e-mail: trevisel@unive.it

This Working Paper is published under the auspices of the Department of Economics of the Ca' Foscari University of Venice. Opinions expressed berein are those of the authors and not those of the Department. The Working Paper series is designed to divulge preliminary or incomplete work, circulated to favour discussion and comments. Citation of this paper should consider its provisional character.

The Working Paper Series
is availble only on line
(www.dse.unive.it/pubblicazioni)
For editorial correspondence, please contact:
wp.dse@unive.it

Department of Economics

Ca' Foscari University of Venice

Cannaregio 873, Fondamenta San Giobbe

30121 Venice Italy

Fax: ++39041 2349210 


\section{Introduction}

During recent years, in the European Union, the issue of job security has become very important. The member states, in fact, are confronted with a "double bind", that can be summed up as the flexibility-security nexus. On one hand, there is a demand for increasing flexibility in order to reinforce the competitiveness of firms, sectors and countries. On the other hand, workers demand job security, wage security and employability (Wilthangen, 2003). This nexus can be addressed by a policy strategy in which both objectives are represented in a more or less integrated manner. More precisely, flexicurity can be defined as a policy strategy that attempts to enhance on one hand, the flexibility of the labor market and, on the other, security notably for weak groups inside and outside the labor market (Wilthangen, 2003). In this respect, the European Union in its 2003 Employment Guidelines for Member States states:

"Member States will facilitate the adaptability of workers and firms to change, taking in account of the need for both flexibility and security [....]. Member States will review and, where appropriate, reform overly restrictive elements in employment legislation that affect labor market dynamics [...]." (Employment Guideline for Member States, EU, 2003)

Looser rules about hiring and firing may make easier for employers to hire workers, thus improving the job prospects of new entrants to the work force such as young people (i.e. flexibility). At the same time, easing these restrictions can also make people, who have already a job, worry more about the risk of losing it (i.e. security). The question is controversial and the difficulty to find effective policy strategies is reflected by the history of the institutional framework of the national labor markets ${ }^{1}$

From the beginning of the 1980's in Spain the high rate of unemployment pushed towards the possible benefits that would derive from increasing flexibility in the labor market. In this view, the first reform introduced in Spain, concerning the liberalization of the temporary contracts in 1984, had as the main goal an increase in flexibility. In the middle of the nineties, the high percentage of temporary workers and the high turnover determined a pressing need for combining flexibility and security. After the poor results obtained in 1994, a new reform, in 1997, aimed at increasing stability.

This reform, differently with respect to the majority of the reforms introduced in the Western Europe in the nineties, was not a reform "at the margin". In fact, instead of introducing further elements of "pure" flexibility (i.e. new kind of temporary contracts), it tried to increase the use of

\footnotetext{
${ }^{1}$ See Oecd (2004) for further considerations about the costs and benefits of greater job security.
} 
permanent contracts by reducing the costs of firing. Moreover, this reform can be viewed as a "natural experiment"2. In particular, a "natural experiment" occurs when some exogenous event - like a change in the government policy - change the environment in which agents operate and the impact of this change can be evaluated comparing the mean before and after the event (Besley and Case, 1994) ${ }^{3}$. The evaluation of the impact of this kind of reforms on labor market has stimulated research ${ }^{4}$ and the nature of "natural experiment" of the Spanish reform represented an interesting base for several studies $^{5}$

This paper evaluates the impact of the 1997 reform in Spain on the perceived job security of the workers. A study of this reform is particularly compelling because, in contrast with the majority of the European reforms, it marks a sharp change for some groups (i.e. young workers, older workers, long-term unemployed, women under-represented in their occupations and disabled workers), while leaving other groups unaffected. This represents an opportunity to set up a treatment-control design that may provide reliable estimates (Kugler et al., 2003).

The novelty of the study is the focus on the impact of the reform on the satisfaction of workers with respect to job security. In fact, the change in the level of job satisfaction among the workers due to changes in the institutional regime is not frequently evaluated despite its increasing importance. There is, instead, an increasing attention towards the determinants of the level of job satisfaction and job security ${ }^{6}$ and less attention about how these levels are affected by the macro aspects of the labor market ${ }^{7}$. In fact, elements like the rate of unemployment, the Employment Protection Legislation (EPL) and the Unemployment Benefit (UI), the previous institutional and economic frameworks affect the perceived job security of the workers and the behavior of the employees significantly; the change on the behavior of the employees could, indirectly, affect the results of the reform. Moreover, changes in the level of perceived job security have several potential broad implications related to investment in job-specific skills, job mobility, con-

\footnotetext{
${ }^{2}$ We consider this reform a natural experiment because it presents the typical characteristics attributed to a natural experiment, i.e. it's an "exogenous" event that affects some targeted groups while leaving unaffected some other groups.

${ }^{3}$ This last feature is particularly valuable because, normally, one reason the causal effect of institutional changes has been difficult to establish is the lack of sharp changes or reform that can be used for measurement. Most institutional changes in the European context have been either so gradual or general that it is difficult to identify control groups that can be used to establish a non-reform baseline necessary for comparison (Kugler et al., 2003)

${ }^{4}$ See, for example, Blanchard and Landier (2002), Acemoglu et al. (2001), Bauer et al. (2004).

${ }^{5}$ See, for example, Kugler et al. (2003), Dolado et al. (2001), Arellano (2004).

${ }^{6}$ See, for example, Clark(1997, 1998), Clark et al. (1996,2001), Givord and Maurin (2003), Manski and Straub (1999).

${ }^{7}$ See, for example, Clark and Postel-Vinay (2005), Clark et al. (2001).
} 
sumption and savings, health job-related issues.

In the empirical analysis data drawn from the European Community Household panel (ECHP) for Spain from 1995 to 2000 are used. The ECHP is a cross sectional longitudinal survey that focuses on household income and living conditions.

In the evaluation analysis I combine the propensity score matching with a fixed effect estimator. The latter gives the possibility to exploit the panel characteristics of our data set while the propensity score matching technique, applied to the treated and untreated groups in 1995, addresses the problem of heterogeneity between treated and control groups.

Given the subjective nature of the variable of interest and the risk of some unobserved heterogeneity, some robustness checks are performed. First of all, I check if there are some evidence of reform's effect on other job satisfaction variables. Secondly, in order to test the robustness of the fixed effect estimation I perform the analysis on the control groups. To conclude, to test in a different way the robustness of our findings, we will estimate the treatment effects using a propensity score matching DID estimator.

The paper is organized as follow. Section 2 gives a brief description of the institutional framework of the Spanish labor market and the 1997 reform. Section 3 presents the data and the empirical model. Section 4 presents the estimations results. Section 5 presents some robustness checks. Finally, section 6 offers some concluding remarks.

\section{The Institutional Framework}

The performance of the Spanish labor market is, among the Oecd countries, one of the most disappointing, with an unemployment rate, during the 1990's, exceeding 20\%. Accordingly, the employment creation has been one of the primary challenges facing the Spanish government since 1980 (Martìn, 2002).

The main peculiarity of the actual institutional framework of the Spanish labor market finds its origins in 1980, with the approval of the Worker's Statute (Ley del Estatuto de los Trabajadores). This law defined the two main institutional features of the Spanish system of labor market relations which, despite several reforms, still remain operative: a high degree of employment protection (EPL) and the predominance of collective bargaining at the provincial/industrial level ${ }^{8}$.

The most significant attempt to reduce the strictness of EPL was the liberalization of the fixed-term contracts in late 1984. This reform introduced a whole variety of temporary contracts which, by contrast to the permanent ones, entailed much lower severance payments, if any, and whose termination couldn't be appealed (Dolado et al., 2001).

\footnotetext{
${ }^{8}$ See Jimeno and Toharia (1993) for further details.
} 
Subsequently, in the middle of 90s, two labor market reforms (1994 and 1997) aimed to reverse the effects of the 1984 liberalization, trying to reduce the proportion of temporary employment. In the early nineties, in effect, one third of the Spanish labor force worked under temporary contracts $(32.5 \%)$ and more than $90 \%$ of all new signed contracts were temporary ${ }^{9}$. In Spain, at the moment, there was a pressing need for combining flexibility with security (Martìn, 2002).

The two main provisions of the reform in 1994 limited the use of temporary contracts to seasonal jobs and widened the conditions for "fair" dismissal. The reform had a weak impact on the Spanish labor market. On one side, the employers continued to hire workers under temporary contracts for all kinds of jobs. On the other side, the approval of dismissal for "economic reason" continued to be granted mainly when there was an agreement between employers and workers, while the labor courts continued to rule most dismissals as unfair.

At the beginning of 1997 , the unemployment rate was $21.5 \%$ and there was a high level of insecure employment. In this context, the employers confederation (CEOE) and the major unions (UGT and CC.OO) reached an agreement to reform the system of employment contracts and the structure of collective bargaining. This reform aimed to reducing the use of temporary contracts by increasing the incentives for the firms to hire workers from certain population groups using permanent contracts. In practise, the reform introduced a new permanent contract with lower firing costs in case of unfair dismissal.

Since 1998, the Spanish government introduced several measures related to working time flexibility. In particular, with the Agreement on Promoting Stable Part Time Employment on 13th November 1998, a series of measures were introduced to promote stable part time employment, permanent intermittent employment and replacement contracts combined with early retirement.

More recently, the 2001 labor reform suppressed the ceiling for the number of part time hours and introduced a more flexible distribution of working hours groups.

\subsection{The 1997 reform}

Until 1997 all the reforms introduced in Spain, and in the Western European countries as well, attempted at increasing flexibility through the liberalization of temporary contracts. People refers to them as "reforms at the margin" because of the failure on introducing a fundamental liberalization. Instead, they may increase the wages of permanent workers (as a consequences of the creation of a dual labor market), having some undesirable consequences for

\footnotetext{
${ }^{9}$ The percentage of temporary contracts in Spain was one of the highest in Europe. See Martìn (2002) for further details.
} 
output, employment and segmentation of the labor market ${ }^{10}$ (Kugler et al., 2003).

The 1997 reform, conversely, represented the first attempt of the Spanish government to correct the distortions of the labor market, due to the large increase in temporary contracts of the previous years and, at the same time, to introduce new elements of flexibility, reducing the dismissal costs for permanent contracts.

This reform had three main characteristics. First, it promoted the use of permanent contracts to hire 18-29 years old, long-term unemployed adults, disabled persons and temporary workers; secondly, it reduced the use of fix term contracts; finally, it promoted combined theoretical and practical education among the young to facilitate their entry into the labor market.

Some of the main incentives introduced by the government were: the reduction of social security contributions ${ }^{11}$; the reduction of dismissal costs during a period of two years for new permanent contracts $^{12}$; the limitation of the number of fix-term contracts that can be offered; the introduction of new training policies.

In practise, the 1997 reform reduced the dismissal costs for unfair dismissals by about $25 \%$ and payroll taxes between $40 \%$ and $90 \%$ for newly signed permanent contracts and for conversions of temporary into permanent contracts, after the second quarter of 1997, for workers under 30 years of age, over 45 years of age, long-term unemployed, women under-represented in their occupations and disabled workers. Severance payments for unfair dismissals of newly signed contracts for the workers in the target groups were reduced from 45 to 33 days pay per year of seniority and the maximum was reduced form 42 to 24 months. The payroll taxes reduction ${ }^{13}$ was $40 \%$ for workers under 30 years of age and for long-term unemployed, $60 \%$ for workers above 45 years of age and women under-represented in their occupations and between $70 \%$ and $90 \%$ for disabled workers. Furthermore, in some cases, payroll taxes were reduced again after the second year of employment (Kugler et al., 2003).

\footnotetext{
${ }^{10}$ See, for example, Blanchard and Landier (2002), Cahuc and Postel-Vinay (2002), Dolado et al. (2001), Hunt (2002), Garcia-Fontes and Hopenhayn (1996), Jimeno and Toharia (1993,1996), Bertola and Ichino (1995), Bentolila and Dolado (1994); and Bentolila and Saint-Paul (1992) for theoretical and empirical analysis of the effect of temporary contracts.

${ }^{11}$ Employers are entitled to these reductions when they hire a persons from one of the target groups and offer them a permanent contract.

${ }^{12}$ These incentives have the aim to remove the barriers which prevent employers from offering such contracts.

${ }^{13}$ In Spain, the average payroll tax rate was about $33 \%$ of the salary of the worker. The uniform payroll tax rate was differentiated by age group and contract. For example, for young workers it was the $28.3 \%$ of the salary. The reduction of $40 \%$ implied a new payroll tax rate of about $16 \%$.
} 


\section{Data and Methodology}

\subsection{Data}

Data are from the European Community Household Panel (ECHP) from 1995 to $2000^{14}$. The ECHP is a cross-sectional longitudinal survey focusing on household income and living conditions: information on health, education, housing, migration, demographics, employment characteristics and satisfaction are provided ${ }^{15}$.

A panel has been extracted from the ECHP for Spain including men and women between 16 and 65 years of age, employed ${ }^{16}$. The panel presents attrition, as typical in a household panel, due to non response and changes in the life of respondents (death, moving, etc.). In Peracchi (2002) the estimated average attrition for Spain is $10 \%$.

The question on job security is inserted in a wide range of questions regarding personal satisfaction of the ECHP questionnaire. The exact wording is as follow:

Question: "How satisfied are you with your present job or business in terms of job security? Using a scale form 1 to 6 , please indicate your degree of satisfaction. Position 1 means that you are not satisfied at all, and 6 that you are fully satisfied"

The typical formulation of this kind of questions contains a subjective element regarding the meaning of "satisfied" or even "job security" that could vary from one person to another (Clark and Postel-Vinay, 2005) ${ }^{17}$

The expected impact of this reform might be ambiguous. First, the reduction of firing costs may increase the probability to access to permanent $\operatorname{contracts}^{18}$, affecting positively the level of job security. Secondly, the layoff procedure became "easier" and this could make the "new permanent" workers (e.g. individuals hired with permanent contracts after 1997) feel less secure.

To conclude, Table 2 and Table $3^{19}$ describe the composition of the sample and of the treatment and the control groups considered in our analysis,

\footnotetext{
${ }^{14}$ We exclude the first (1994) and the last wave (2001): the first one because there are no workers hired with permanent contracts; the last one because, in the same year, another reform that modifies and extends the 1997 refomr, has been introduced. This reform modifies and extends the one occurred in 1997.

${ }^{15}$ See Peracchi (2002) for further details.

${ }^{16}$ The questions related to job satisfaction are asked only to employees. See Tab. 1 in the Appendix B for composition of the sample.

${ }^{17}$ This implies that it could be not compared across individuals or countries in a obvious way. Considering the kind of estimation analysis we are going to exploit this element has to be taken in account.

${ }^{18}$ See Kugler et al. (2003).

${ }^{19}$ See Appendix B.
} 
respectively. The treatment and the control groups differ for some characteristics, as sex, marital status, number of children, level of education, kind of contract (permanent and temporary), sector (public or private), experienced past unemployment: the so-called observable pre-treatment characteristics that require a proper control.

\subsection{The identification strategy}

The aim of this paper is to investigate the effect of the reduction on dismissal costs on the level of perceived job security.

The variable on interest is the perceived job security of the worker that, as all the satisfaction variables, is a categorical variable (it takes the value 1-6: not satisfied-fully satisfied), with an underlying ordinal utility, that is transformed into cardinal linearizing the outcome variable: any translation into numbers is suitable,provided that the order of the "values" is preserved (Van Praag et al., 2003). Each observation of the ordinal output variable is set equal to the expected mean of a truncated normal distribution ${ }^{20}$.

Two different treatment groups are identified: the first group is composed by individuals under 30 years of age and the second by individuals above 45 years of age $\mathrm{e}^{21}$. In each of the two treatment groups the individual are temporary workers and they are entitled, after the reform, to be hired with the new permanent contracts (i.e. permanent contracts with lower firing costs). Four control groups are constructed. The first is composed by individuals with less than 30 years of age, working with a "traditional" permanent contract; the second by temporary workers with an age between 30 and 36 years; the third by permanent workers with more than 45 years of age; finally, the fourth by temporary workers with an age between 38 and 44 years.

The first treatment group (i.e. temporary workers with less than 30 years of age) is compared, first, with permanent workers with less than 30 years of age and, secondarily, with temporary workers with an age between 30 and 36 years. In the same way, the second treatment group (i.e. temporary workers with more than 45 years of age) is compared with the control group composed by permanent worker with more than 45 years of age and with the group of temporary workers with age between 38 and 44 years (Table 1 ).

\footnotetext{
${ }^{20}$ See Appendix A for further details.

${ }^{21}$ We don't consider the long-term unemployed because we cannot observe them. We exclude also the women under-represented in their work place because they may be selfselected (Kugler et al., 2003). We exclude also the disabled workers because of a lack of observations.
} 
Tab. 1: Treatment and control groups comparisons.

\begin{tabular}{|l|l|}
\hline \hline Treatment groups & Control groups \\
\hline Below 30 with temporary contracts & Below 30 with permanent contracts \\
\hline Below 30 with temporary contracts & Age 30-36 with temporary contracts \\
\hline Above 45 with temporary contracts & Above 45 with permanent contracts \\
\hline Above 45 with temporary contracts & Age 38-44 with temporary contracts \\
\hline \hline
\end{tabular}

To each treatment group two control groups are assigned. In the first case treated and untreated have the same age, but different contracts (temporary and permanent respectively); in the second case, treated and untreated have the same temporary contract but different age ${ }^{22}$.

Figures 1 and 2, show that the treatment group composed by temporary workers with less than 30 years of age presents a change in the level of perceived job security starting in 1997. After the reform, this group presents an increasing level of job security. The first control group (i.e. permanent workers with less than 30 years of age), instead, presents a more stable pattern along all the period. The second control group, finally, has a less stable pattern in the period of analysis, without showing a precise trend.

Considering the second treatment group (see figure 3 and 4) there is no evidence of same effect on the level of perceived job security induced by the reform. In fact, in the observed period, the perceived job security of the target group doesn't change, as well as the level of job security of the first control group (i.e. permanent workers with more than 45 years of age). As before, the pattern of the second control group is less stable than that of the first control, but there is no evidence of a trend change.

\footnotetext{
${ }^{22}$ The first control group is composed by individuals who are in a better situation than the treated; the second control group is composed by individuals who are in a worse situation than the treated.
} 
Fig. 1: Average level of job security for the "below 30" treatment group versus the "below 30" control group (yearly means)

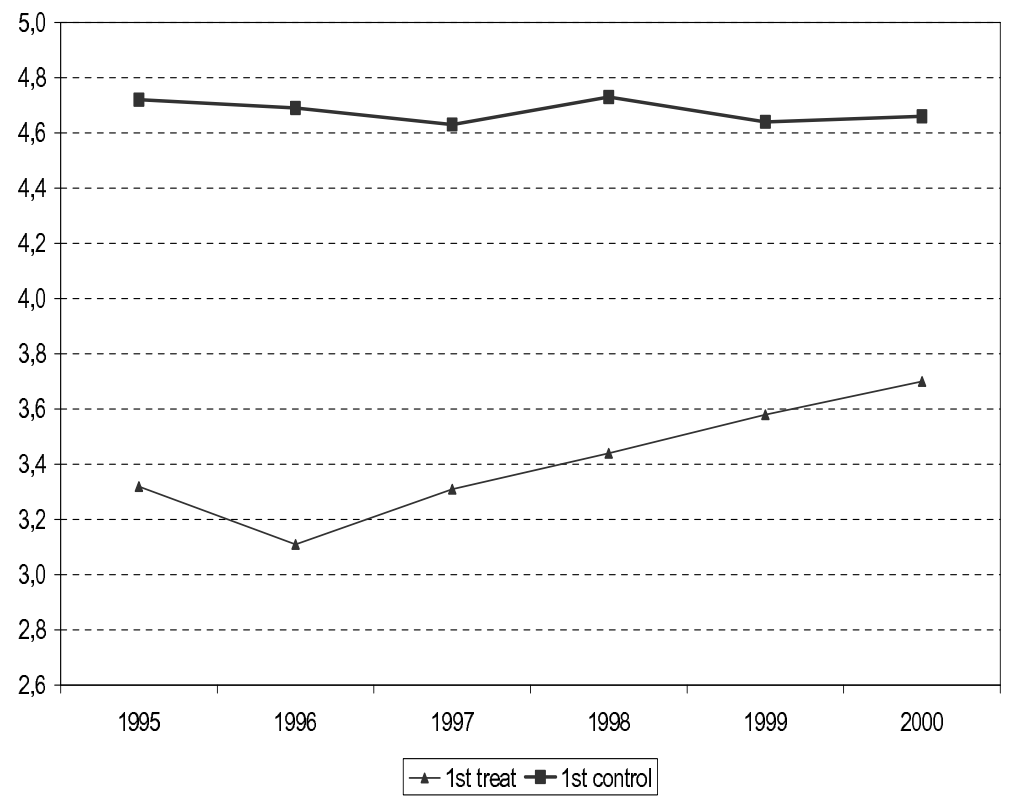

Note: ECHP dataset.

Fig. 2: Average level of job security for the "below 30" treatment group versus the "age 30-36" control group (yearly means)

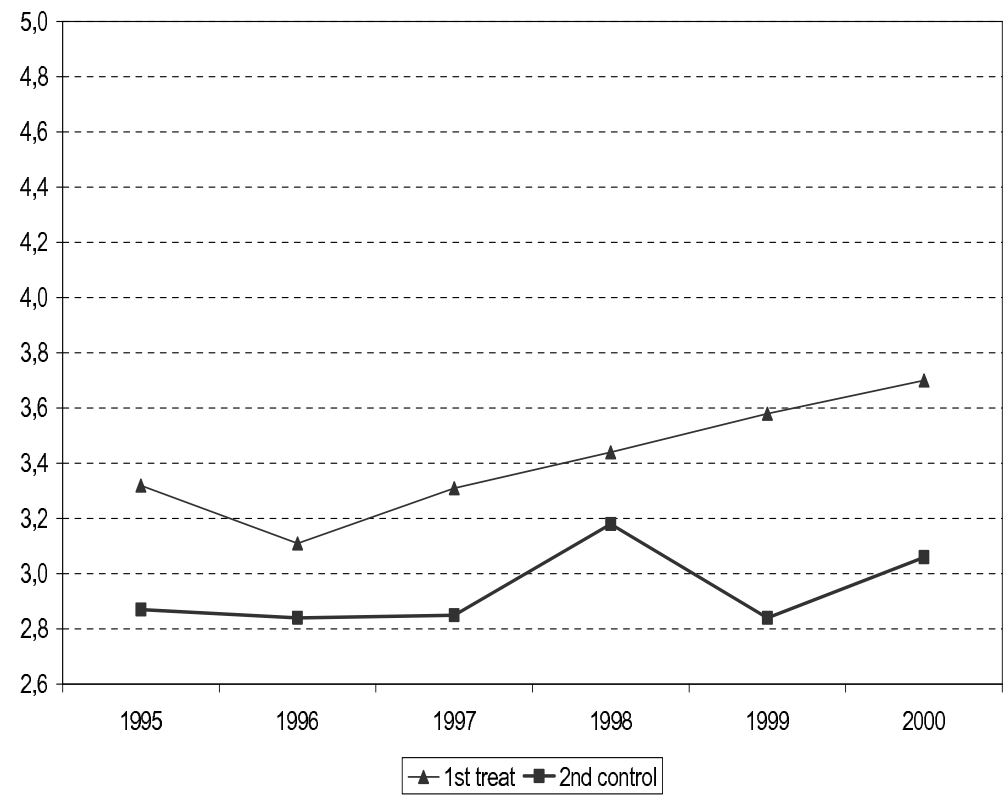

Note: ECHP dataset. 
Fig. 3: Average level of job security for the "Above 45" treatment group versus the "Above 45" control group (yearly means)

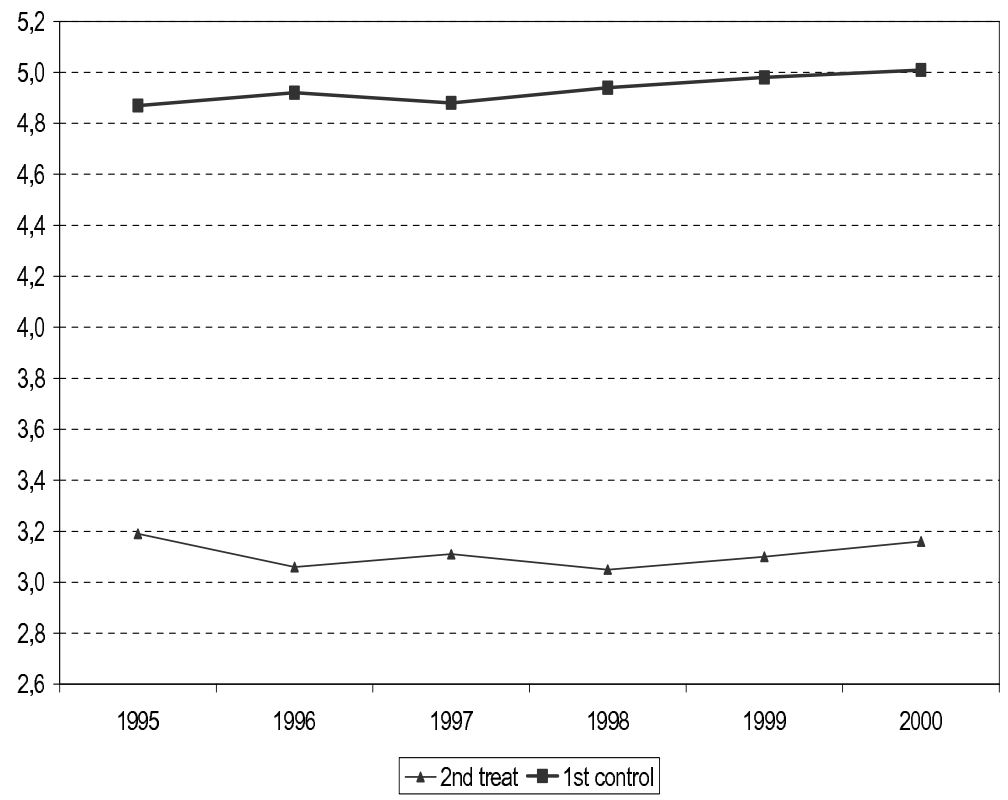

Note: ECHP dataset.

Fig. 4: Average level of job security for the "Above 45" treatment group versus the "age 38-44" control group (yearly means)

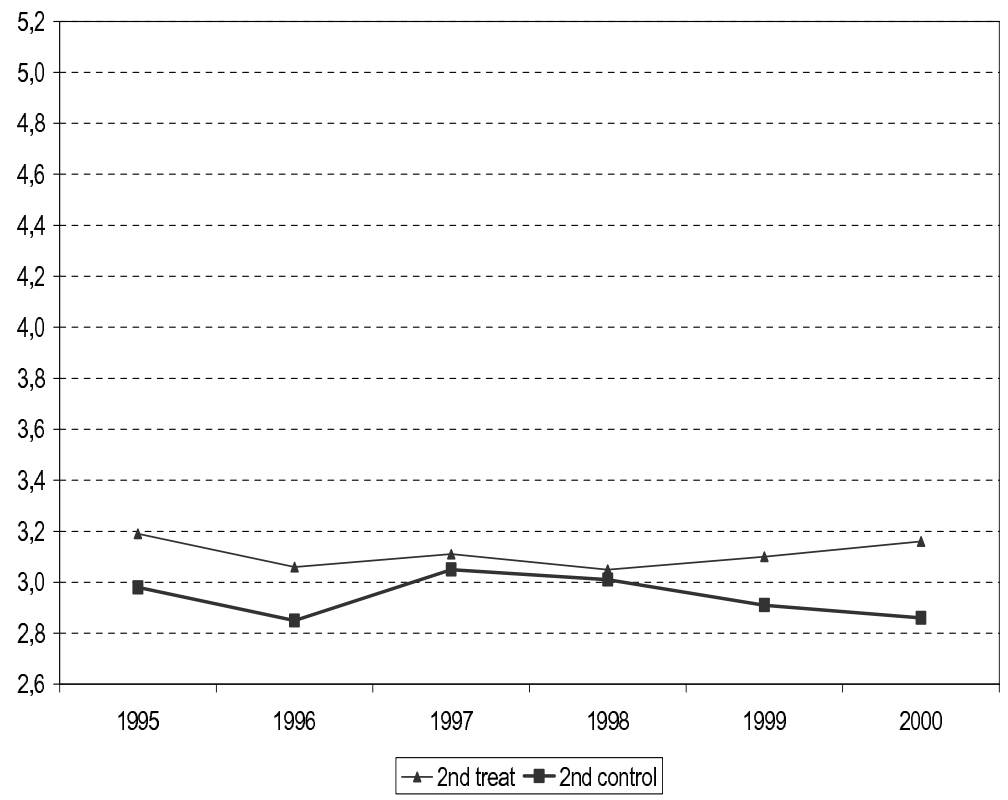

Note: ECHP dataset. 
The presence of observable differences between the treatment and the control groups requires the use of a set of control variables: demographic variables ${ }^{23}$, variables related to the job conditions and income ${ }^{24}$.

\subsection{Estimation strategy}

\subsubsection{The traditional Differences-in-Differences estimator}

In a natural experiment, the most used estimation strategy is based on the Differences-in-Differences (DID) estimator. The DID allows a comparison between a pre-treatment and a post-treatment outcome for those individuals exposed to the treatment, using an untreated comparison group (the so-called control group) to control for temporal variations of the outcome that are not due to the treatment exposure (Abadie, 2005).

The basic DID framework can be described as follow. Let $Y(i, t)$ be the outcome of interest for individual $i$ at time $t$. The population is observed in a pre-treatment and a post-treatment period. Let's denote $t=0$ in the former case and $t=1$ in the latter case. Between these two periods a fraction of the population is exposed to the treatment. Similarly, let's denote $D(i, t)=1$ if individual $i$ is exposed to the treatment and $D(i, t)=0$ otherwise (Abadie, 2005).

The conventional DID estimator is often specified using a linear parametric model:

$$
Y(i, t)=\gamma_{0}+\gamma_{1} t+\gamma_{2} D(i, t)+\gamma_{3} t \cdot D(i, t)+\varepsilon(i, t)
$$

$\hat{\gamma}_{3}$ is the Differences-in-Differences estimator:

$$
\hat{\gamma}_{3}=\left(\bar{\gamma}_{D=1, t=1}-\bar{\gamma}_{D=1, t=0}\right)-\left(\bar{\gamma}_{D=0, t=1}-\bar{\gamma}_{D=0, t=0}\right)
$$

that measures the effect of the treatment.

The DID estimator is based on a crucial and critical assumption. The error term has to be uncorrelated with the other variables (e.g. $\left.\operatorname{cov}\left(\varepsilon_{i}, D_{i}, t_{i}\right)=0\right)$. This means that the average outcomes of the treated and the untreated, in absence of treatment, would have followed parallel paths over time (Abadie, 2005).

This is implausible if the pre-treatment characteristics, associated with the dynamics of the outcome variable, are unbalanced between treated and control groups. As a consequences the estimator will be biased (Abadie, 2005).

\footnotetext{
${ }^{23}$ Sex, age, age squared, level of education (high, medium and low), marital status, immigrant status, number of children.

${ }^{24}$ Professional level (manager or professional, intermediate, blue-collar), sector (private or public), economic sector, working hours (full time or part time), size of the firm, experience in the labor market, experience of past unemployment, length of the unemployment spell, income of the household.
} 
As shown by Heckmann et al. (1998), this bias can be split in three parts: a first component due to the non overlapping support (i.e. the populations have completely different characteristics, $\mathrm{X}$ ), a second due to the different distributions of $\mathrm{X}$, within the two populations, a third due to the differences in outcomes that remain even after controlling for the first two biases ${ }^{25}$.

The differences in observed characteristics, in fact, might create non parallel dynamics in the perceived job security for the treated the untreated. The bias due to differences in the characteristics and their distribution within group might become relevant and the evaluation problem could not be addressed with the traditional DID.

Looking at figures 1 to 4 , I could notice that in the pre-reform period the treatment and the control groups don't seem to follow parallel paths in all the comparison considered. These empirical evidence, then, support the fact the basic assumption of the DID estimator is not valid.

\subsubsection{The propensity score matching and the fixed effect estima- tor}

Two main aspects have to be considered to set up the evaluation strategy in a proper way. The first relates to the heterogeneity between and within treatment and control groups. The second refers to the panel characteristics of our sample.

Given these considerations, the empirical strategy used is composed by three step. First, the panel has been balanced in order to have the same individuals in all the years considered. In this way, I address the problem related to the heterogeneity over time, due to the possibility that in different years the treatment and the control groups could be composed by different individual. Secondly, to control for heterogeneity between groups, the treatment and the control groups are matched on the basis of a set of pre-treatment observable characteristics, using a propensity score matching method.

The propensity score is defined by Rosembaum and Rubin (1983) as the conditional probability of receiving a treatment given the pre-treatment characteristics:

$$
P(X) \equiv \operatorname{Pr}\{D=1 \mid X\}=E\{D \mid X\}
$$

where $D=\{0,1\}$ is the indicator of exposure to treatment and $X$ is the multidimensional vector of pre-treatment characteristics.

Several methods are available in order to match treatment and control groups

\footnotetext{
${ }^{25}$ The latter is the selection bias and it is due to the selection of the unobservables. This kind of bias can become less relevant if, as in our case, the data are administrated with the same questionnaire and the treated and the untreated reside in the same local labor market (Heckmann et al., 1997).
} 
on the basis of the propensity score ${ }^{26}$. I use the Kernel Matching method that matches all the treated with a weighted average of all controls, with weights that are inversely proportional to the distance between the propensity score of the treated and the controls (Becker and Ichino, 2002). In particular, the kernel weight function is:

$$
W(i, j)=\frac{G\left(\frac{P_{j}-P_{i}}{a_{n}}\right)}{\sum_{k \in I_{0}} G\left(\frac{P_{k}-P_{i}}{a_{n}}\right)}
$$

where $G($.$) is the kernel function and a_{n}$ is a bandwidth parameter.

Formally, two hypothesis are needed in the matching process in order to derive, successively, the treatment effect. The balancing property of treatment variables $^{27}$, as well as, the unconfoundeness given the propensity score must hold $^{28}$ (Becker and Ichino, 2002).

The use of the propensity score addresses properly the issue of common support and miss-weighting ${ }^{29}$. In fact, the balancing property of the propensity score implies that observations with the same propensity score must have the same distribution of observable characteristics independently of the treatment status (Becker and Ichino, 2002). Furthermore, the matching method links to each treatment a control unit having the closest propensity score. Eventually, the treatment effect of the reform on the perceived job security of the worker, using a fixed effect estimator on the matched and balanced sample is estimated.

In practice, we estimate the following equation:

$$
Y_{i}=\alpha_{i}+\delta_{t}+\gamma D_{i, t}+\beta D_{i, t} \text { Post }_{1997}
$$

where $\alpha_{i}$ indicates the individual effect, $\delta_{i}$ indicates the time effect, $D_{i, t}$ is a dummy variable that assume value 1 when the individual is treated and 0 otherwise, Post Pog7 $_{19}$ is a dummy variable that assumes value 1 if we observe the post reform period and 0 otherwise. $\beta$ is the parameter of interest that measures the effect of the reform. The key assumption of this approach is that the unobservables $\alpha_{i}$ (i.e. individual effects) are time invariant (Cameron and Trivedi, 2005).

The fixed effect model has the attraction of allowing one to use panel data to establish causation under weaker assumption than those needed to establish causation with cross-section data or with panel data models without fixed

\footnotetext{
${ }^{26}$ The most common methods are: Nearest Neighbor Method, Radius Matching, Kernel Matching and Stratification Matching.

${ }^{27}$ If $P(X)$ is the propensity score, then $D \perp X \mid p(X)$.

${ }^{28}$ Suppose the assignment to the treatment is unconfounded, i.e. $Y_{1}, Y_{0} \perp D \mid X$ (CIA unconditional independence assumption). Then, assignment to treatment is unconfounded given the propensity score, i.e. $Y_{1}, Y_{0} \perp D \mid p(X)$.

${ }^{29}$ See Heckman et al. (1997).
} 
effects, such as pooled models and random effects models (Cameron and Trivedi, 2005).

\section{Results}

The aim of the reform introduced in Spain in 1997 was to reduce the instability in the labor market through a new restrictive permanent contract. The expected effect on the level of perceived job security might be ambiguous. On one hand, an increase in the level of job security for the target groups, due to an increasing probability to access to permanent contract, is expected. On the other hand, the reduction of firing costs, that accompany this contract, can introduce a higher level of insecurity among the workers. In practise, the final effect of the introduction of these new restrictive permanent contracts depends on the concern of the workers with respect to the higher probability to be hired and the higher probability to be fired.

To analyze the impact of this reform we use a fixed effect estimator after having matched treatment and control groups on the basis of the propensity score technique.

The aim of combining these two techniques is to solve the problem of heterogeneity of the treatment and the control groups and to use the panel characteristics of our sample as well. In fact, the variable of interest is a measure of the subjective perception of the workers about the possibility to lose their job and, several worker's characteristics as age, gender, kind of contract, past experiences of unemployment could affect significantly the perceived job security (see, for example, Clark (1997, 1998), Clark et al. $(1996,2001,2005))$.

For this reason, we first balance the panel, then we obtain the propensity score $^{30}$ and we identify, for each participant, all non participants who match on the propensity score ${ }^{31}$, using kernel weights. Finally, on these matched samples we estimate the treatment effects of the reform using a fixed effect estimator. A separate analysis for blue-collar workers has also been performed.

Tab. 4 reports the estimation results.

The reform has a positive and significant effect for the temporary workers with less than 30 years of age, in both the comparisons performed. This results is coherent with the literature on the relationship between job security and strictness of EPL. In Clark and Postel-Vinay (2005), for example, the authors, using data from ECHP for 12 European countries, found a negative relationship between job security and job protection, i.e. workers feel less

\footnotetext{
${ }^{30}$ To estimate the propensity score (See Becker and Ichino (2002)) we use a set of demographic variables and some related to the job conditions of the individuals. See footnotes 22 and 23 .

${ }^{31}$ See Leuven and Sianesi (2003).
} 
secure in countries where the jobs are more protected. Also in Spain, the reduction of strictness of EPL seems to have introduced a higher sense of security. On the other hand, our results are coherent also with the conclusions of Kugler et al. (2003), who investigate the impact of the reform on the probability of transition between different states. They noticed an increasing probability, in particular for young individuals, to move from temporary to permanent employment.

There is no effect instead on the perceived job security for the workers more than 45 years old. This is explained by the fact that for this group together with an higher probability to move from temporary to permanent permanent positions, there is an higher probability of transition from permanent employment to non employment as well ${ }^{32}$.

These results are confirmed also by the analysis performed only on the bluecollar workers. The temporary workers with less than 30 years of age show an increase in the perceived job security due to the introduction of the reform in both comparisons. Table 5 shows the estimation results.

\section{Sensitivity Analysis}

\subsection{The outcome variable}

The outcome variable of our analysis - the perceived job security of the workers - is subjective and this might rise some doubts about the estimation results. In other words, it might be that the effect captured by our estimator is affected by subjective bias even after controlling for individual characteristics.

One way to check for the existence of a possible subjective bias is to explore the overall satisfaction with respect to job and other dimensions related or unrelated to the changes introduced by the 1997 reform.

The ECHP questionnaire contains a set of satisfaction questions related to different aspects of the job conditions. I plot the yearly average level of different satisfaction variables for the first treatment group - i.e. temporary workers with less than 30 years of age - and the first control group, composed by permanent workers with less than 30 years of age ${ }^{33}$. In figure 5 , the overall job satisfaction variable that comes out from the following question:

How much satisfied are you with your work or main activity?

The answers are ranked from 1 to 6 , where 1 means not satisfied and 6 fully satisfied.

\footnotetext{
${ }^{32}$ See Kugler et al. (2003).

${ }^{33}$ In the paper, we propose this check only for the first treatment-first control groups comparison and only for some satisfaction variable for simplicity reasons. For more detailed information, please ask to the author.
} 
Fig. 5: Average level of job satisfaction for the "below 30" treatment group versus the "below 30" control group (yearly means)

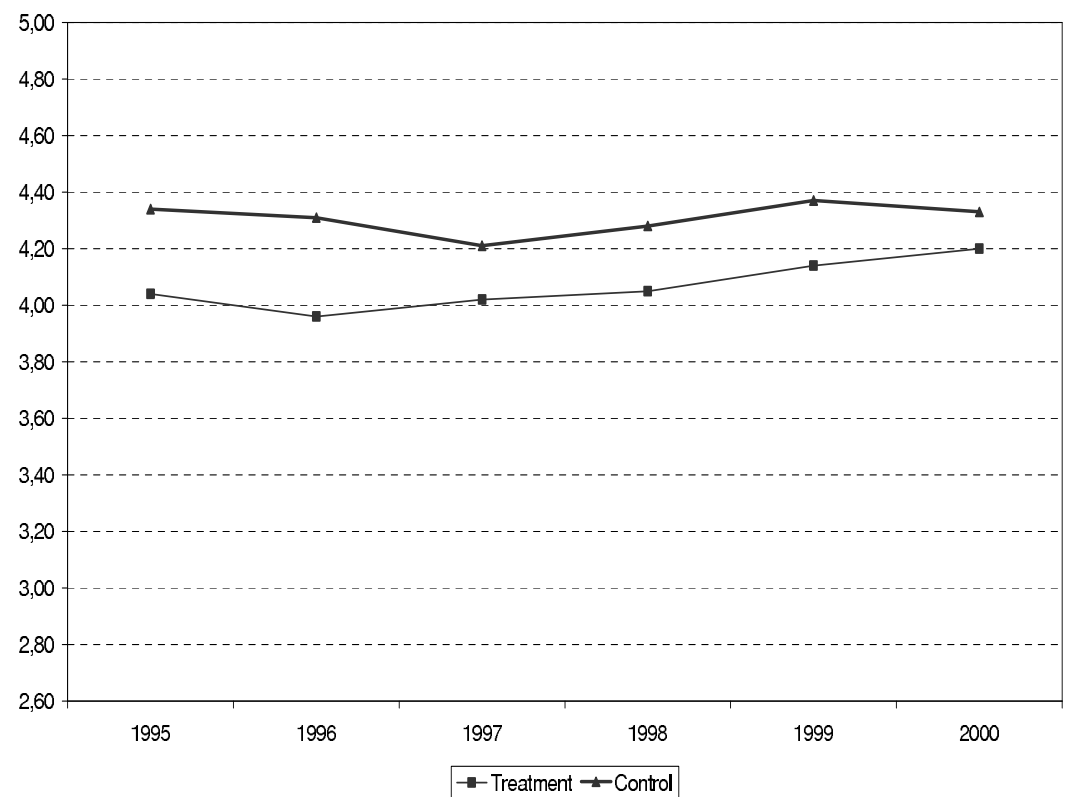

Note: ECHP dataset.

The overall job satisfaction of the treated is increased starting from 1996 and there is not a specific change after the 1997 reform. The control group, on the other side, shows a similar increasing pattern on the level of job satisfaction, since the year of the reform. Moreover, the differences in the level of job satisfaction among the two groups is not so wide as in case of the perceived job security.

The satisfaction related to the distance from the workplace is interesting because it's totally unrelated to the reform. The question is:

How satisfied are you with your present job in terms of distance to job/commuting?

Figure 6 makes clear that there are no changes in the level of the satisfaction after the 1997 reform both for treatment and control groups and, moreover, they both follow the same pattern. 
Fig. 6: Average level of distance satisfaction for the "below 30" treatment group versus the "below $30 "$ control group (yearly means)

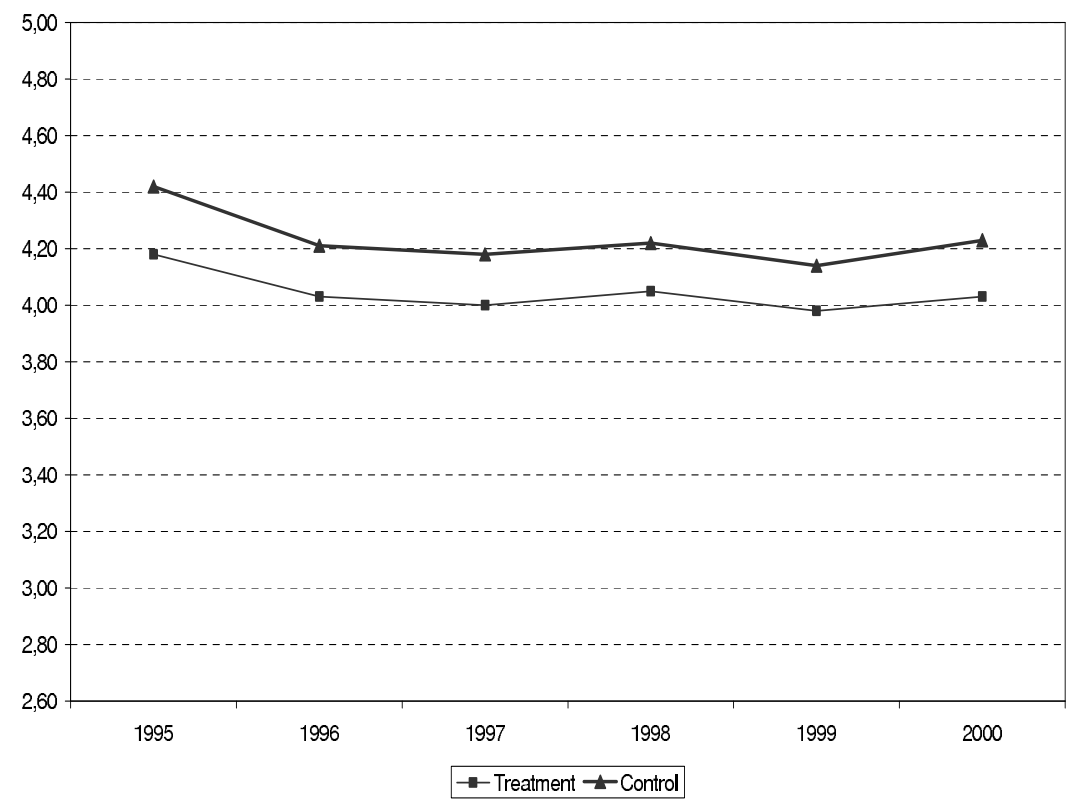

Fig. 7: Average level of working time satisfaction for the "below 30" treatment group versus the "below 30 " control group (yearly means)

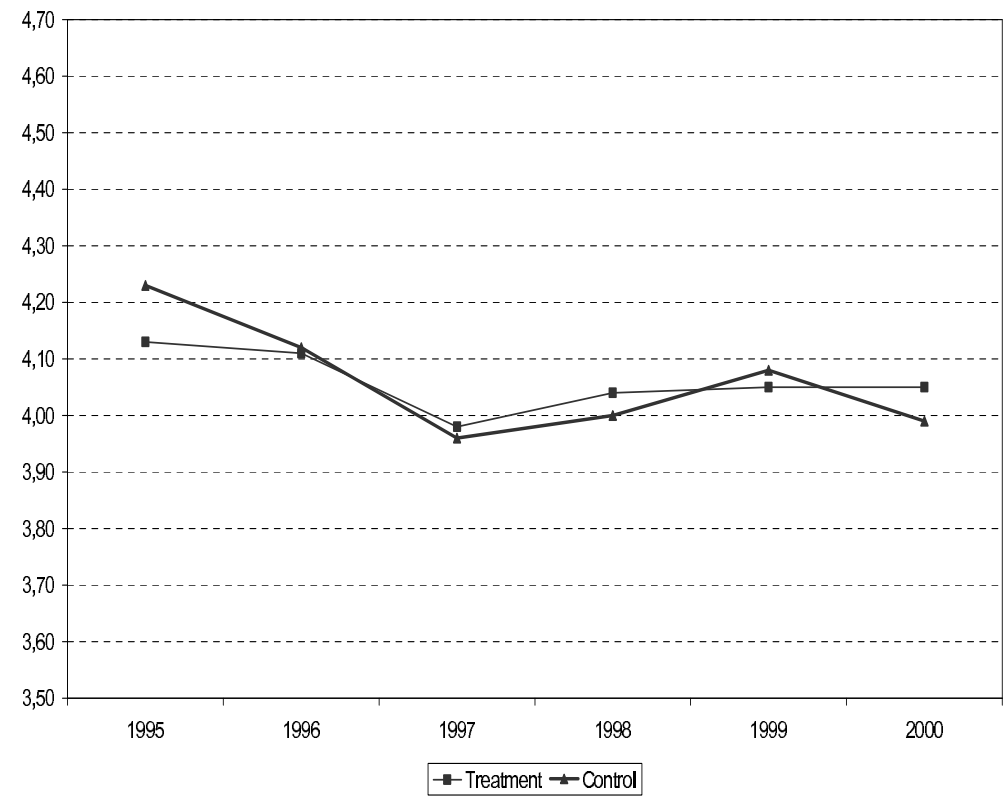

Note: ECHP dataset. 
Figure 7 and 8, represent the yearly average level of satisfaction related to working time and working/environment conditions respectively. The two question are:

How satisfied are you with your present job in terms of working times (day time, night time, shifts, etc.)?

How satisfied are you with your present job in terms of working conditions/environment?

Also in these cases, there are no clear changes in variables trajectories after the 1997 reform and the two groups follow the same pattern and have almost the same level in respect to both working times and working conditions satisfaction.

Fig. 8: Average level of environment satisfaction for the "below 30" treatment group versus the "below 30" control group (yearly means)

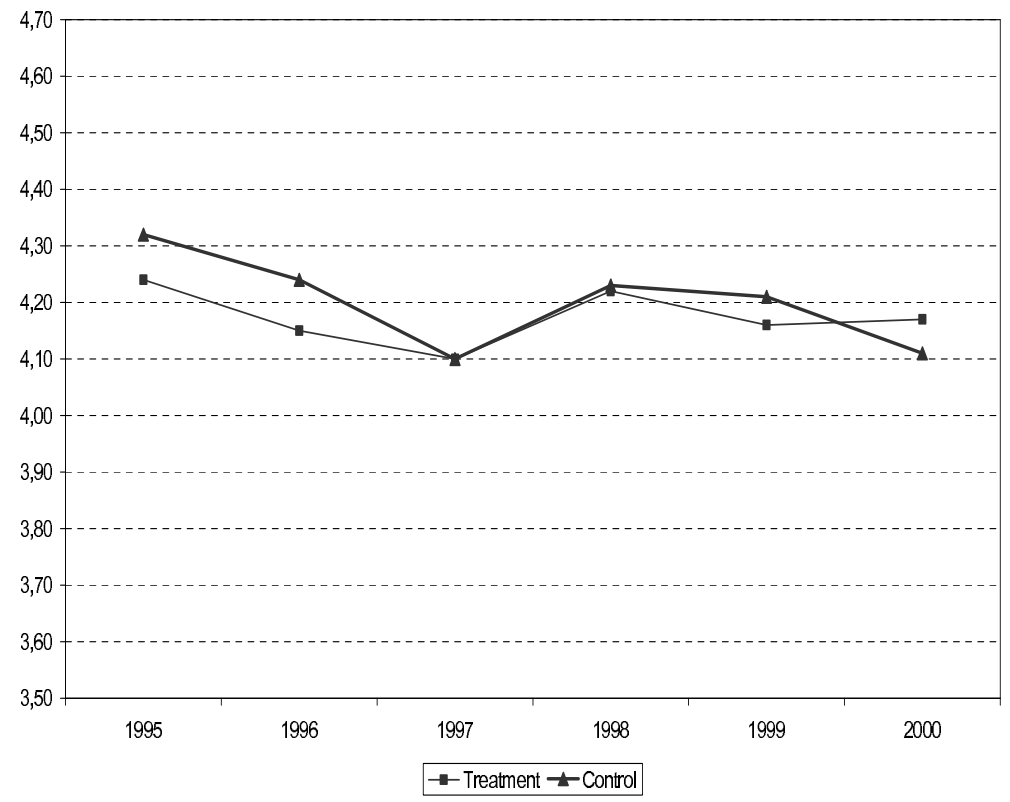

Note: ECHP dataset.

At the end, the reform's impact estimated on the perceived job security of the workers seems to capture the real effect and not a subjective bias, given that the other job satisfaction variables are not affected by the reform. 


\subsection{The fixed effect analysis of the control groups}

The application of the fixed effect estimation technique to the control groups allows to test the correctness of the group construction and the possible heterogeneity between treated and untreated. In case of correct set up of our analysis, the coefficient $\gamma$ - i.e. the coefficient related to the treatment/control dummy - should be 0 and there should not be any treatment effect, i.e. $\beta$ not significantly different from 0 .

More specifically, I estimate the equation (5) twice. In the first case, D should be equal to 1 if individuals are permanent workers with less than 30 years of age (i.e. first control group related to first treatment group) and 0 if individuals are permanent workers with more than 45 years of age (i.e. first control group related to second treatment group). In the second case, D should be equal to 1 if individuals are temporary workers with age between 30 and 36 (i.e. second control group related to first treatment) and 0 if individuals are temporary workers with age between 38 and 44 years (i.e. second control group related to second treatment). In both cases, the coefficients $\gamma$ and $\beta$ are not significantly different from $0^{34}$.

\subsection{The propensity score matching DID}

The robustness of the results obtained with the fixed effect estimator is checked by performing the same analysis using a propensity score matching DID estimator. First, we balance the panel in order to have the same individuals each year. Secondly, in each year we match treatment and control groups on the basis of the propensity score ${ }^{35}$, using kernel matching technique. Finally, we evaluate the differences-in-differences for couples of year (i.e one year after the reform versus one year after the reform). This procedure will be done for each treatment-control comparison. The structure of the analysis is as follows:

Tab. 1bis: Differences-in-Differences structures.

\begin{tabular}{|l|l|}
\hline \hline DID & Structure \\
\hline$D I D_{98-95}$ & $A T T_{1998}-A T T_{1995}$ \\
\hline$D I D_{99-95}$ & $A T T_{1999}-A T T_{1995}$ \\
\hline$D I D_{00-95}$ & $A T T_{2000}-A T T_{1995}$ \\
\hline$D I D_{98-96}$ & $A T T_{1998}-A T T_{1996}$ \\
\hline$D I D_{99-96}$ & $A T T_{1999}-A T T_{1996}$ \\
\hline$D I D_{00-96}$ & $A T T_{2000}-A T T_{1996}$ \\
\hline
\end{tabular}

Table 6 shows the estimation results. The treatment effects estimated with the propensity score matching DID confirm the results obtained with the

\footnotetext{
${ }^{34}$ For detailed results, please contact the author.

${ }^{35}$ For the variables used in the definition of the propensity score see footnotes 22 and 23.
} 
fixed effect analysis. There is a positive and significant effect for the temporary workers with less than 30 years of age in both the comparisons with the two control groups in almost all the cases. There are no effects for the temporary workers with more than 45 years of age.

\section{Conclusion}

This paper uses the labor market reform, that occurred in Spain in 1997, introducing new restrictive permanent contracts characterized by lower dismissal costs and lower payroll taxes. The 1997 reform represents a "natural experiment" and allow us to set up a research design to evaluate its impact on the perceived job security of some target groups of Spanish workers.

The introduction of these new restrictive permanent contracts could produces a double effects. One side the probability to be hired with a permanent contract is higher - and this rises the sense of security of the workers - on the other it becomes easier to be fired and this, of course, makes the worker feel insecure. Estimates using ECHP data for Spain suggest that the reform increased the perceived job security for workers with less than 30 years of age and there were no effect for workers with more than 45 years of age.

The results are robust even using the blue-collar workers' sample and the propensity score matching DID technique.

In previous studies ${ }^{36}$ the relationship between job security and strictness of EPL is found to be negative. This means that high level of Employment Protection is associated with low level of security and viceversa.

Our analysis, then, confirms that in Spain, the introduction of looser EPL did increase the job security and changed the distribution of the perceived job security from less to more satisfied position in the satisfaction ranking.

\footnotetext{
${ }^{36}$ See, for example, Clark and Postel-Vinay (2005).
} 


\section{References}

[1] Abadie A. (2005), "Semiparametric Differences-in-Differences Estimators", Review of Economics Studies, 72(1): 1-19.

[2] Acemoglu D., Angrist J. (2001), "Consequences of Employment Protection? The Case of the Americans with Disabilities Act", Journal of Political Economy, 109(5): 915-57.

[3] Arellano F.A. (2004), "Evaluating the Effects of Labor Market Reforms "at the margin" on Unemployment and Employment Stability: The Spanish Case", Universidad Carlos III Economics Working Paper No. we051205.

[4] Bauer T.K., Bender S., Bonin H. (2004), "Dismissal Protection and Workers Flows in Small Establishment", IAB Discussion Paper No. $1 / 2004$.

[5] Becker S.O., Ichino A. (2002), "Estimation of Average Treatment Effects Based on Propensity Score", Stata Journal, 2(4): 358-77.

[6] Bentolila S., Dolado J.J. (1994), "Labor Flexibility and Wages: Lessons From Spain", Economic Policy, 9(18): 53-99.

[7] Bentolila S., Saint-Paul G. (1992), "The Macroeconomic Impact of Flexible Labour Contracts, with an Application to Spain", European Economic Review, 36(5): 1013-1047.

[8] Bertola G., Ichino A. (1995), "Crossing the River: A Comparative Perspective on Italian Employment Dynamics", Economic Policy, 0(21): 359-415.

[9] Besley T., Case A. (1994), "Un-natural experiment? Estimating the Incidence of Endogeneous Policies", NBER Working Paper No. 4856.

[10] Blanchard O., Landier A. (2002), "The Perverse Effects of Partial Labor Maket Reform: Fixed Duration Contracts in France", Economic Journal, 112: F214-F244.

[11] Cahuc P., Postel-Vinay F. (2002), "Temporary Jobs, Employment Protection and Labor Market Performance", Labour Economics, 9(1): 6392.

[12] Cameron A.C., Trivedi P.K. (2005), Microeconometrics - Methods and Applications, Cambridge University Press, New York.

[13] Clark A., Oswald A.J., Warr P.B. (1996), "Is Job Satisfaction U-Shaped in Age?", Journal of Occupational and Organizational Psychology, 69: $57-81$. 
[14] Clark A. (1997), "Job Satisfaction and Gender: Why Are Women So Happy at Work?", Labour Economics, 4: 341-72.

[15] Clark A. (1998), "Measures of Job Satisfaction. What Makes a Good Job? Evidence From Oecd Countries", Labour Market and Social Policy - Oecd Occasional Paper No. 34.

[16] Clark A., Georgellis Y., Sanfey P. (2001), "Scarring: The Psychological Impact of Past Unemployment", Economica, 68: 221-41.

[17] Clark A., Postel-Vinay F. (2005), "Job Security and Job Protection", IZA Discussion Paper No. 1489.

[18] Dolado J.J., Garcia-Serrano C., Jimeno-Serrano J.F. (2004), "Drawing Lessons From the Boom of Temporary Jobs in Spain", CEPR Discussion Papers No. 2884.

[19] European Union (2003), Employment Guidelines for Member States", Official Journal of the European Union, available on-line http://europa.eu.int/comm/employment_social/employment_strategy.

[20] Garcia-Fontes W., Hopenhayn H. (1996), "Creaciòn y Destrucciòn de Empleo en la Economìa Española", in Ramon Marimon, ed. La Economia Espagñola: una Vission Diferente. Barcelona: Antoni Bosch Editor.

[21] Givord P., Maurin E. (2003), "Changes in Job Security and Their Causes: An Empirical Analysis for France, 1982-2002", European Economic Review, 48: 595-615.

[22] Heckman J.J., Ichimura I., Todd P.E. (1997), "Matching as an Econometric Evaluation Estimator: Evidence from Evaluating a Job Training Programme", The Review of Economic Studies, 64(4): 605-654.

[23] Heckman J.J., Hichimura I., Todd P.E. (1998), "Characterizing Selection Bias Using Experimental Data", Econometrica, 66: 1017-98.

[24] Hunt J. (2000), "Firing Costs, Employment Fluctuations, and Average Employment: An Examination of Germany", Economica, 67(266): 177202.

[25] Jimeno J.F., Toharia L. (1993), "The Effects of Fixed-Term Employment on Wages: Theory and Evidence from Spain", Investigaciones Econòmicas, XVII(3): 475-94.

[26] Jimeno J.F., Toharia L. (1996), "Effort, Absenteeism, and Fixed Term Employment Contracts", Revista Española de Economia, 13(1): 105119. 
[27] Kugler A., Jimeno-Serrano J.F., Hernanz V. (2003), "Employment Consequences of Restrictive Permanent Contracts: Evidence from Spanish Labor Market Reforms", CEPR Discussion Paper No. 3724.

[28] Leuven E., Sianesi B. (2003), "PSMATCH2: Stata Module to Perform Full Mahalanobis and Propensity Score Matching, Common Support, Graphing, and Covariate Imbalance Testing", http://ideas.repec.org/c/boc/bocode/s432001.html.

[29] Maddala G.S. (1986), Limited Dependent and Qualitative Variables in Econometrics, Cambridge University Press, New York.

[30] Manski C.F., Straub J.D. (1999), "Worker Perceptions of Job Insecurity in the Mid-1990s: Evidence From the Surveys of Economic Expectations", NBER Working Paper No. 6908.

[31] Martìn S.G. (2002), "An Overview of Spanish Labor Market Reforms, 1985-2002", Unidad de Politicas Comparadas - CISC - Working Paper No. 02-17.

[32] OECD (1997), Employment Outlook, Paris.

[33] OECD (2004), "Employment Protection: The Costs and Benefits of Greater Job Security", OECD Policy Brief.

[34] Peracchi F. (2002), "The European Community Household Panel: A Review", Empirical Economics, 27: 63-90.

[35] Rosembaum P.R., Rubin D.B. (1983), "The Central Role of the Propensity Score in Observational Studies for Causal Effects", Biometrika, 70(1): 41-55.

[36] Smith J., Todd P.E. (2000), "Does Matching Overcome the Lalonde's Critique of Nonexperimental Estimators?", University of Western Ontario, CIBC Human Capital and Productivity Project WP No. 20035.

[37] Van Praag B.M.S., Frijters P., Feller-i-Carbonell A. (2003), "The Anatomy of Subjective Well-Being", Journal of Economic Behavior \& Organization", 51: 29-49.

[38] Wilthagen T., Tros F., Van Lieshout H. (2003), "Towards 'Flexicurity'? Balancing Flexibility and Security in EU Member States", invited paper 13th World Congress of the International Relations Association, Berlin. 


\section{A Truncated normal distribution}

Let us suppose that the random variable $X$ is $N(0,1)$, and we consider the truncated distribution $X \geq c_{1}$. The mean of this truncated distribution is given $b^{37}$ :

$$
E(X)=\frac{\phi\left(c_{1}\right)}{1-\Phi\left(c_{1}\right)}=\frac{\text { ordinate at } X=c_{1}}{\text { right hand tail area }}=M_{1}
$$

If the truncation is from above, so that we consider the distribution $X \leq c_{2}$, then:

$$
E(X)=\frac{-\phi\left(c_{2}\right)}{\Phi\left(c_{2}\right)}=M_{2}
$$

If the distribution is double truncated, so that we consider $c_{1} \leq X \leq c_{2}$, then:

$$
E(X)=\frac{\phi\left(c_{1}\right)-\phi\left(c_{2}\right)}{\Phi\left(c_{2}\right)-\Phi\left(c_{1}\right)}=M
$$

In the analysis, $\mathrm{X}$ is the ordered variable describing the level of job security, $c_{1}$ and $c_{2}$ are respectively the level 1 and 6 of the satisfaction ranking. Following the previous procedure and a new continuous variable (i.e. security_pols) is created, simply setting security_pols $s_{i}=E\left(\right.$ security_sat $\mid \mu_{i-1}<$ security_sat $\leq$ $\left.\mu_{1}\right)$.

\footnotetext{
${ }^{37}$ See Maddala (1986) for further details.
} 


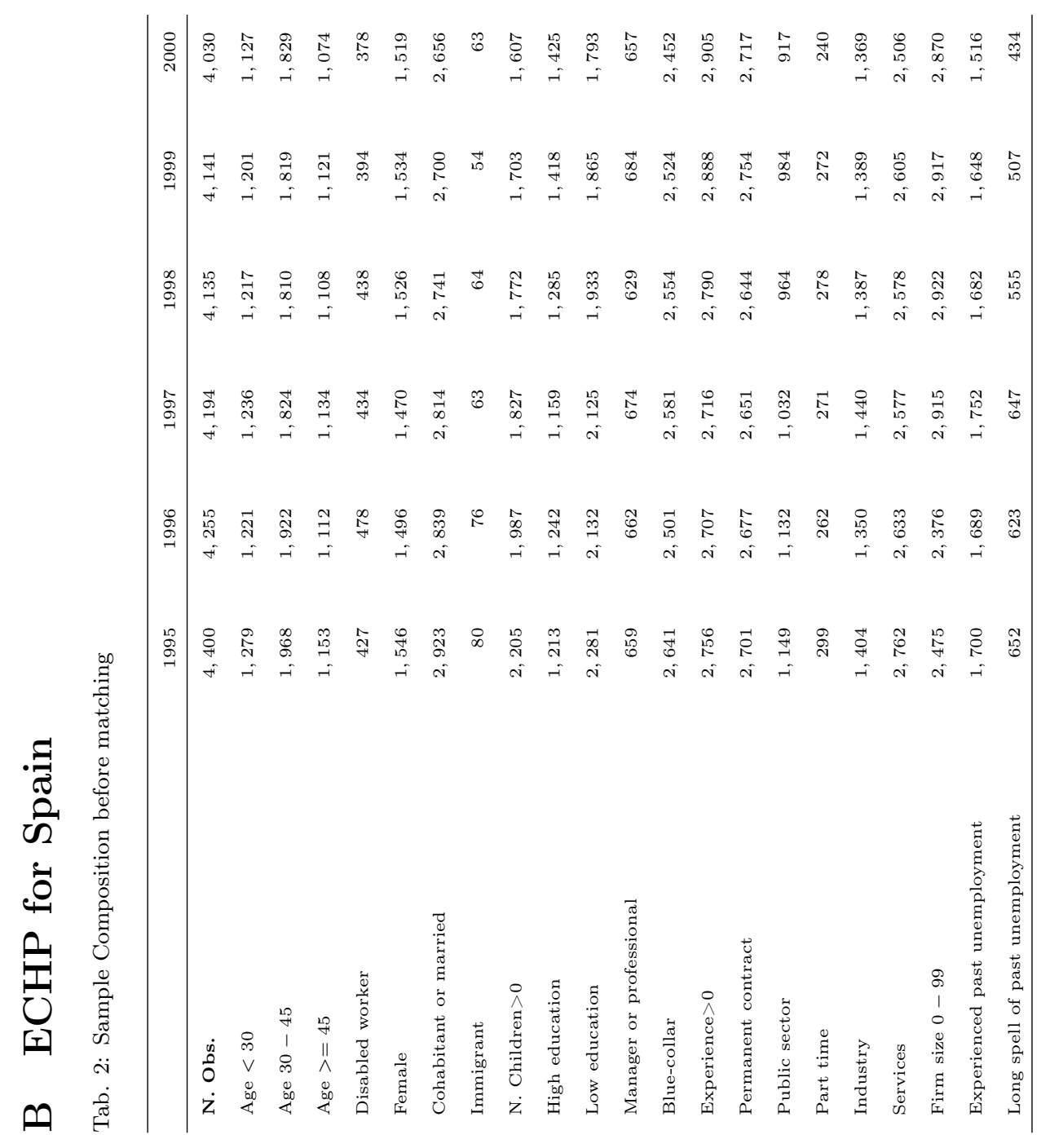




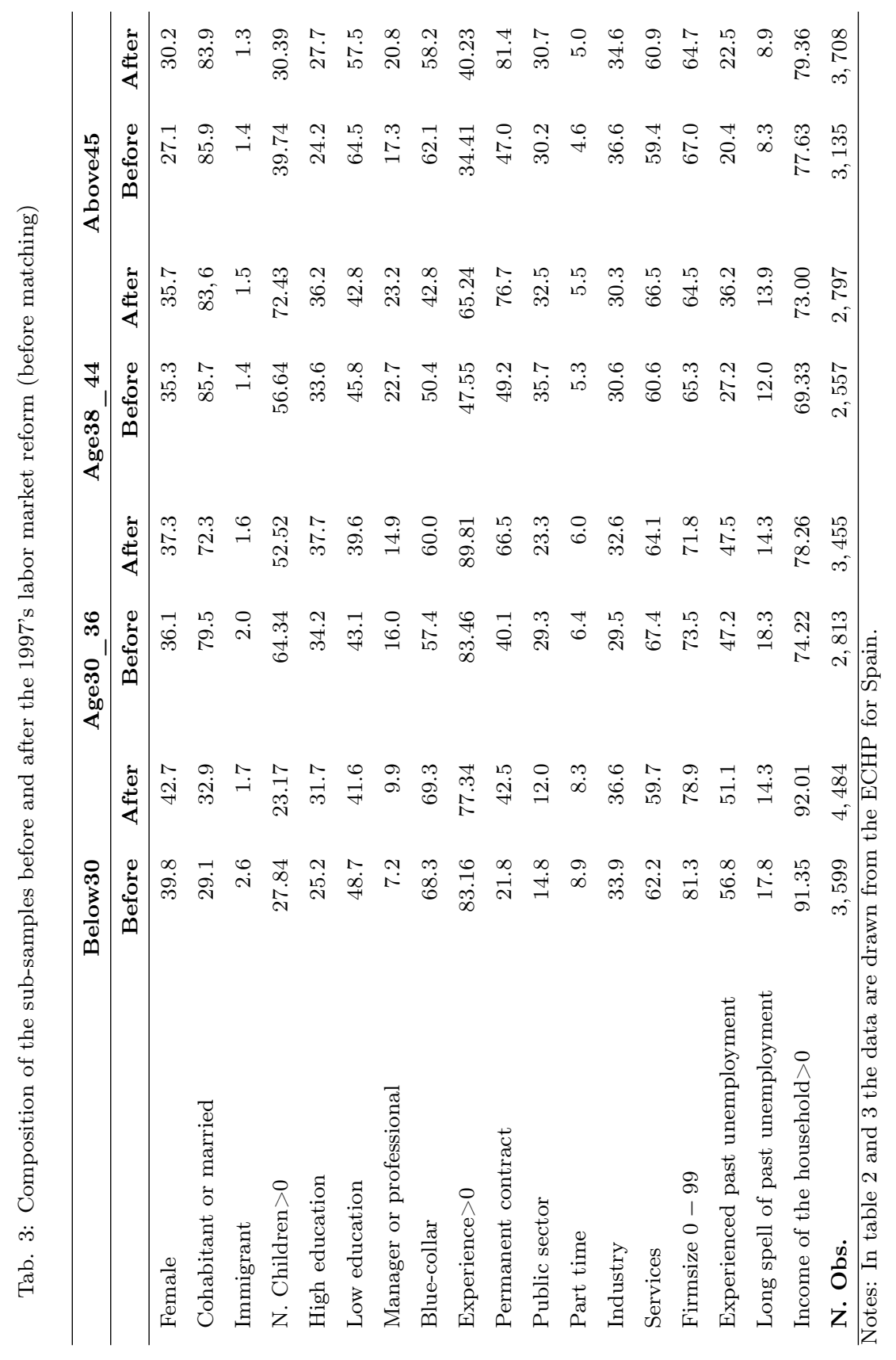




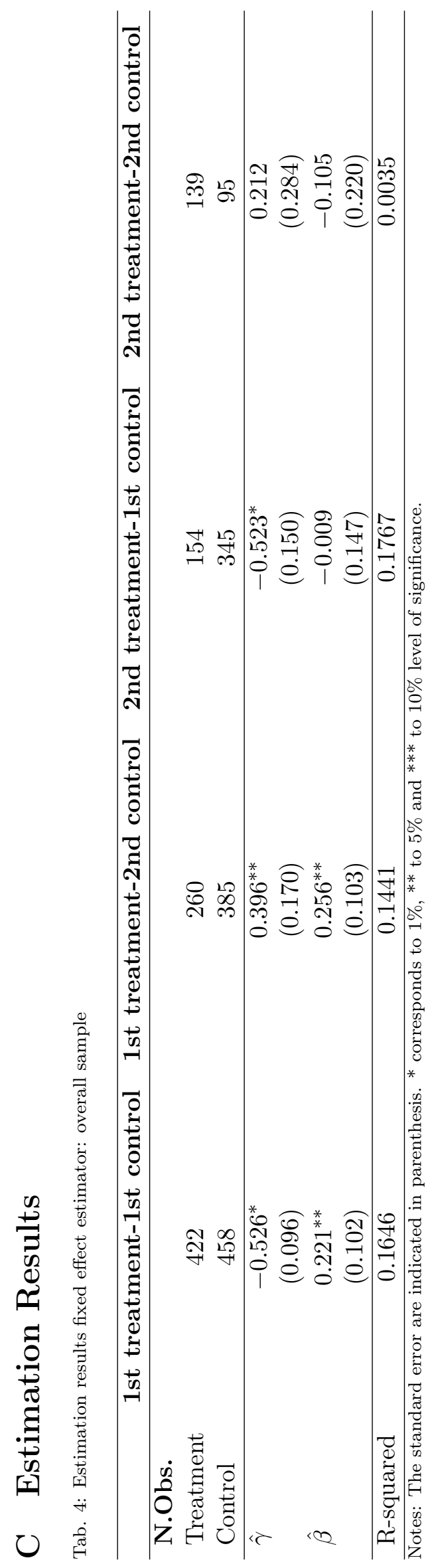




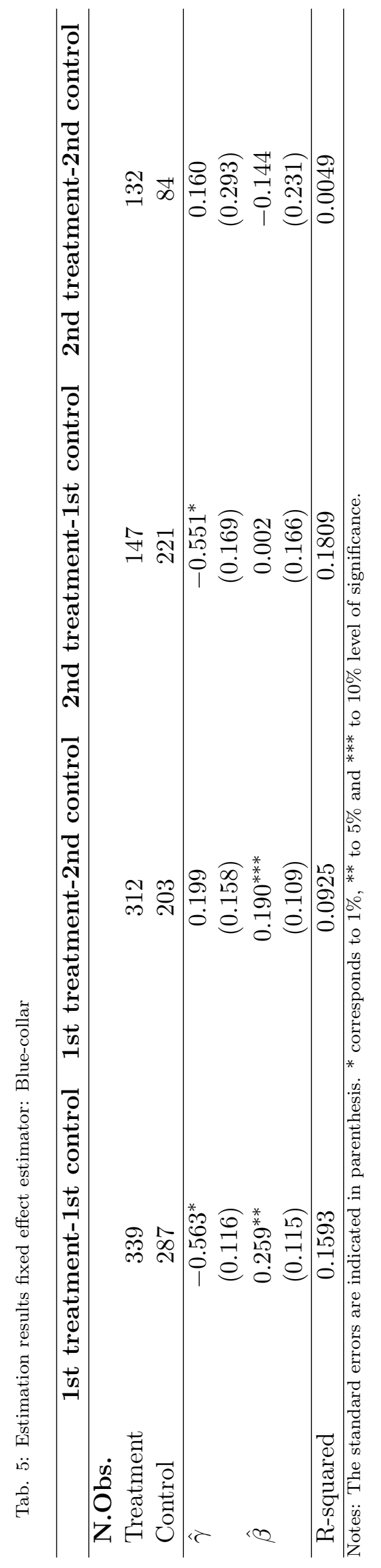




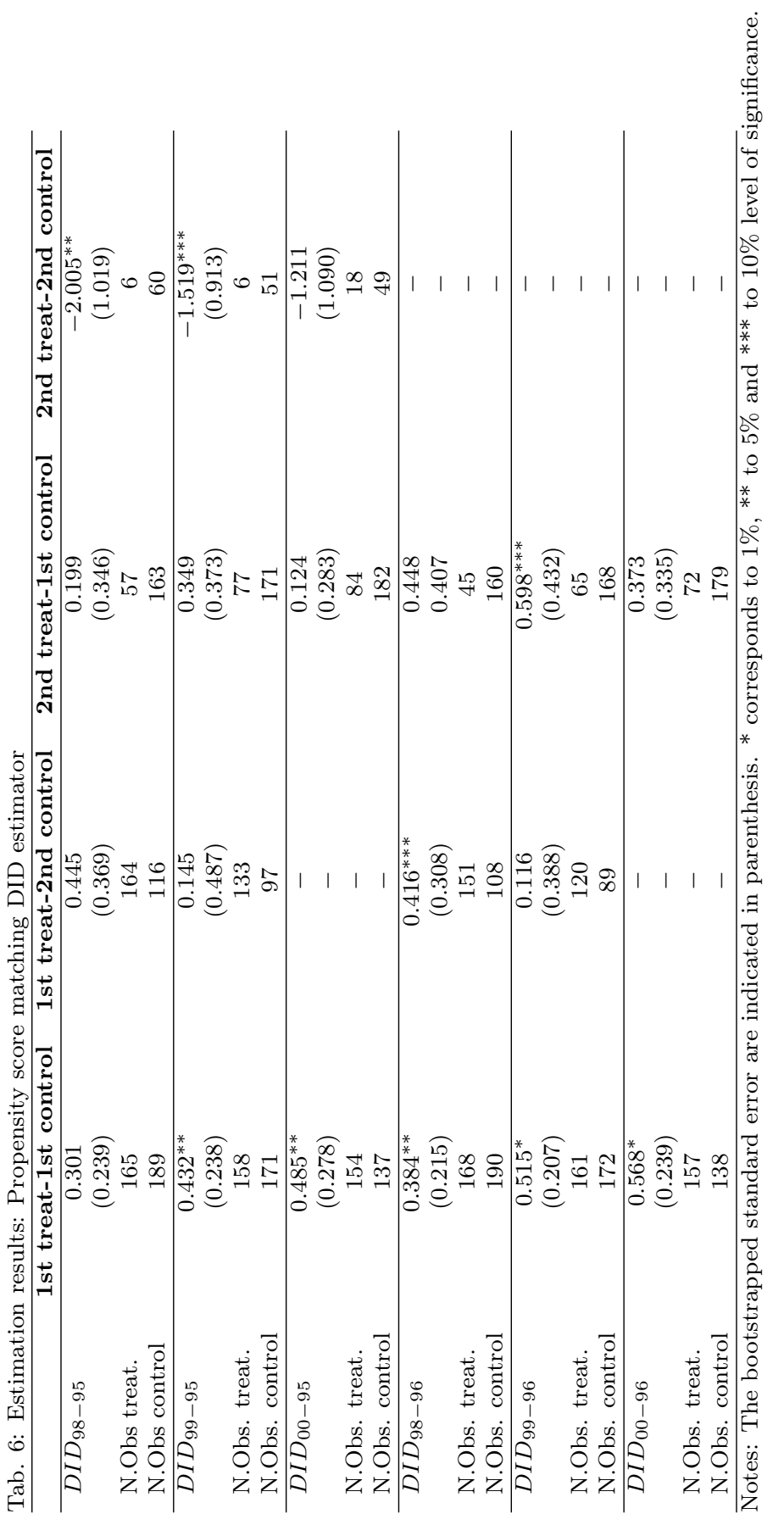

